Cadernos de História, Belo Horizonte, v. 22, n. 36, Junho de 2021

DOI: https://doi.org/10.5752/P.2237-8871.2021v22n36p146-161

\section{O INDÍGENA PELO OLHAR DE GonÇALVES Dias: UMA REPRESENTAÇÃO MULTIFACETADA NAS OBRAS "Primeiros CANTOS" E "Segundos Cantos"}

Eduardo Oliveira Melo

Universidade E. da Região Tocantina do Maranhão oliveiramello839@outlook.com

RAIMUNDO Lima dos SANTOS

Universidade E. da Região Tocantina do Maranhão raimundosantos81@gmail.com

\title{
RESUMO
}

O presente artigo visa realizar uma análise histórica das obras "Primeiros Cantos" e "Segundos Cantos" do poeta maranhense Gonçalves Dias, estabelecendo um diálogo entre história e literatura, de modo a compreender seu olhar sobre o indígena, figura capital em sua poética. A análise dos poemas adota a teoria das representações de Roger Chartier, buscando apreender a complexa trama entre condições socioculturais de produção, a vida do poeta, a emergência do romantismo e as políticas indigenistas do século XIX. Nesse sentido, foi possível desvelar o retrato do indígena como um símbolo de força do império brasileiro, recém-independente, bem como instrumento de crítica do projeto estatal de assimilação das populações indígenas enquanto cidadãos, o que permitiu oferecer um contraponto a certas interpretações da crítica literária que descartam a historicidade dos textos. Demonstra-se, além disso, os interesses do literato na sua busca por reconhecimento no campo da literatura nacional, o que o impeliu certas decisões durante a construção poética. Por último, perscruta-se, brevemente, a literatura contemporânea e posterior ao escritor, expondo a perenidade da sua concepção do indígena.

Palavras-chave: Gonçalves Dias; Indígena; Representação; História; Literatura.

Recebido em 20 de outubro de 2020.

Aprovado em 19 de janeiro de 2021. 
Cadernos de História, Belo Horizonte, v. 22, n. 36, Junho de 2021

DOI: https://doi.org/10.5752/P.2237-8871.2021v22n36p146-161

\section{THE INDIGENOUS THROUGH THE EYES OF GONÇALVES DIAS: A MULTIFACETED REPRESENTATION IN THE WORKS "Primeiros CANTOS" AND "Segundos Cantos"}

Eduardo Oliveira Melo

Universidade E. da Região Tocantina do Maranhão oliveiramello839@outlook.com

RAIMUNDo Lima dos SANTOS

Universidade E. da Região Tocantina do Maranhão raimundosantos81@gmail.com

\begin{abstract}
This article aims to make a historical analysis of the works "Primeiros Cantos" and "Segundos Cantos" by the Maranhão's poet Gonçalves Dias, establishing a dialogue between history and literature, in order to understand his view of the indigenous, a capital figure in his poetics. The analysis of the poems adopts the theory of representations by Roger Chartier, seeking to apprehend the complex relation among socio-cultural conditions of production, the poet's life, the emergence of romanticism and the indigenous policies of the 19th century. In this sense, it was possible to unveil the portrait of the indigenous as a symbol of strength of the Brazilian empire, newly independent, as well as an instrument of criticism of the state project of assimilation of indigenous populations as citizens, which allowed to offer a counterpoint to certain interpretations of literary criticism that disregard the historicity of texts. Furthermore, it demonstrates the interests of the literary in his search for recognition in the circuit of national literature, which impelled him to certain decisions during the poetic construction. Finally, it examines, briefly, the contemporary and subsequent literature to the author, showing the continuity of his conception of the indigenous.
\end{abstract}

Keywords: Gonçalves Dias; Indigenous, Representation, History, Literature. 


\section{INTRODUÇÃO}

O romantismo é um fenômeno que resiste às definições concretas. A extensão de suas manifestações, bem como sua heterogeneidade interior, leva, como advertiu Alfredo Bosi (2017, p. 95), à instrumentalização de seus motivos e temas como forma de mascarar a impossibilidade de uma sólida conceituação. No entanto, historicamente, é lícito situá-lo, na perspectiva de Nachman Falbel (2013, p. 24), enquanto movimento artístico e literário iniciado na Europa, que ganha força em fins do século XVIII, marcado pelo contexto transformador da Revolução Industrial e da Revolução Francesa, e perdura até meados do século XIX. Suas raízes se estenderam para além-mar, encontrando em um Brasil recémindependente, o terreno fértil para o seu nacionalismo impetuoso. Entre os seus principais representantes, figura o poeta maranhense Antônio Gonçalves Dias.

Nascido em 1823, na cidade de Caxias, Gonçalves Dias é celebrado, segundo Antonio Candido (2000, Vol. 2, p. 72-73), como um grande literato consolidador da poesia nacional, estimável influência para os românticos posteriores, não apenas pelo seu indianismo, do qual foi, e ainda é símbolo máximo, mas, igualmente, devido sua concepção da natureza e seu gênio cambiante, rígido, mas melancólico, além de sua perícia em traduzir na métrica seus sentimentos e emoções. Dentre as diversas temáticas de sua lira destacam-se o amor, a natureza, a nação e o indígena. Esse último, emergindo enquanto pedra angular de suas "Poesias americanas", principiadas na primeira parte do livro "Primeiros Cantos" de 1847, retornando em "Segundos Cantos" de 1848, no poema "Tabira".

$\mathrm{O}$ indígena, imagem capital da poesia gonçalvina, pode ser interpretado como uma representação, conceito que o historiador Roger Chartier (2002, p. 19-20) definiu duplamente enquanto forma de exibição de algo ausente e demonstração de uma presença. Toma-se, portanto, a representação como ferramenta para tradução das posições e interesses dos indivíduos perante a sociedade, a qual é redesenhada aos moldes de suas concepções internalizadas ou como seus desejos os impelem. E uma vez que "as percepções do social não são de forma alguma discursos neutros" (CHARTIER, 2002, p. 17), a representação do indígena arquitetada por Gonçalves Dias certamente traz em seu cerne classificações, parcialidades, objetivos pessoais, intenções políticas, entre tantas outras categorias de influência possíveis.

Ao se considerar o estudo de uma representação presente em uma obra poética, é indispensável a reflexão, sob a ótica de Luís Felipe Ribeiro (1996, p. 27-28), quanto ao surgimento de um fetichismo textual nas pesquisas do campo literário, que relegam o elemento humano do texto, isto é, o criador da literatura, consequência direta dos privilégios concedidos à obra como único artefato para o conhecimento, enquanto os elementos históricos e sociais que, seguramente, marcam o processo criativo são perdidos. Dessa forma, o que se propõe nesse artigo é estabelecer um diálogo entre a história e a literatura que concilie o texto, o cenário sociocultural de sua concepção, além da pessoalidade daquele que concebe a obra.

Para tal empreitada, faz-se necessário o cruzamento da efígie indígena presente nos poemas dos livros "Primeiros Cantos" e "Segundos Cantos" com um amplo corpus de documentos portadores das ideias sobre o estatuto das populações nativas. Essa vasta documentação circulava em diversos âmbitos da vida intelectual brasileira, a saber, na arte, ciência e política, originando publicações de crítica literária nas revistas, estudos científicos, 
cartas e legislações. Partindo dessas fontes, através das lentes da história, é possível trazer à tona aspectos da representação do indígena que uma análise puramente literária não poderia.

Por fim, uma breve consulta ao panorama literário brasileiro contemporâneo e póstumo à obra de Gonçalves Dias, revela a força de sua representação do indígena que, apesar de não ser a primeira das letras nacionais, acabou por se consolidar, determinando, crucialmente, a trajetória que outros poetas e escritores tomariam no decorrer do desenvolvimento das temáticas e motivos capazes de transpor o Brasil em criação poética.

\section{O INDÍGENA: ENTRE O NACIONALISMO E A RUÍNA}

No Brasil oitocentista, as populações indígenas estavam circunscritas em um complexo cenário de medidas estatais diversas - em 1808, por meio de Carta Régia, Dom João declara guerra aos chamados "botocudos" e a qualquer nação indígena na capitania de Minas Gerais, permitindo também a escravização dos prisioneiros. Em outras regiões, como explicitou Patrícia Melo Sampaio (2011, p. 183), possivelmente, ainda vigoravam as políticas de aldeamento tanto do "Diretório que se deve observar nas povoações dos índios do Pará, e Maranhão, enquanto sua majestade não mandar o contrário" de 1758, como medidas derivadas e reformuladas deste. O estado imperial legislaria sobre a questão indígena somente em 1845, com o "Regulamento das missões de catequeses e civilização dos índios".

De modo paralelo, o indígena adquiria espaço nas reflexões para a consolidação da literatura nacional. No contexto de pós-independência, os intelectuais intuíam a necessidade de se buscar uma literatura autenticamente brasileira, que fizesse jus às riquezas naturais do novo mundo e ao jovem império. O historiador francês Ferdinand Denis, em seu "Résumé de l'histoire littéraire du Portugal, suivi du résumé de l'histoire littéraire du Brésil” de 1826, já notava a possibilidade de uma literatura brasileira independente da portuguesa:

\footnotetext{
Mas para que essa se constituísse realmente, julgava necessário desenvolver os aspectos nacionais. Neste sentido, propõe a rejeição da mitologia greco-latina que, fundando-se na simbolização da natureza, não pode corresponder à do Novo Mundo; sugere a descrição desta e o aproveitamento, como tema, tanto do índio quanto dos primeiros colonos. (DENIS apud CANDIDO, 2000, Vol. 1, p. 282).
}

Mais tarde, em seu artigo "Sobre a historia da litteratura (sic)" de 1836, na revista "Nitheroy" - importante meio de difusão internacional da intelectualidade brasileira -, Gonçalves de Magalhães preconiza o nacionalismo como alicerce para a formação da literatura brasileira. Nesse intento, propõe como possibilidade o nativo: "Pode o Brasil inspirar a imaginação dos Poetas? E os seus indígenas cultivaram por ventura a Poesia?”. (NITHEROY, 1836, p. 153)

No ramo dos estudos historiográficos, Karl Friedrich Philip von Martius em seu "Como se deve escrever a história do Brasil" de 1845, vencedor do concurso do Instituto Histórico e Geográfico Brasileiro, argumentará a favor de uma história que leve em consideração as três "raças" que fundaram a população brasileira. Além de explicitar a necessidade de se aprofundarem as pesquisas sobre os aspectos físicos, linguísticos, sociais e cosmológicos dos autóctones, uma vez que partilham da influência sobre a síntese que é o povo brasileiro.

Logo depois, em 1847, Gonçalves Dias emerge na cena literária nacional com os seus 
"Primeiros Cantos", em que será o indígena, um dos elementos mais marcantes. A despeito de não ser o primeiro na literatura brasileira a tomar o autóctone como inspiração poética, vide Basílio da Gama, em "Uruguai”, ou Santa Rita Durão, em "Caramuru”, o poeta maranhense investiu em sua representação o simbolismo da nacionalidade e da independência.

Ao olhar para as populações nativas, Gonçalves Dias enxergava o início de toda história e identidade brasileira. Em seu artigo crítico "Reflexões sobre os Annaes Historicos do Maranhão por Bernardo Pereira de Berredo (sic)”, escreve:

O primeiro topico de que havemos de tratar na historia do Brasil é o dos Índios. [...] Elles são instrumento do quanto aqui se praticou de util ou de glorioso; são o principio de todas as nossas cousas; são os que derão a base para o nosso carater nacional; ainda mal desenvolvido, e será a corôa da nossa prosperidade o dia da sua inteira reabilitação (sic). (GUANABARA, 1850, p. 28-29).

Vislumbrando no indígena elevado símbolo da singularidade brasileira, Gonçalves Dias tomou por incumbência arquitetar uma representação vigorosa e concreta, com o intuito de inspirar um sentimento nativista de pertencimento. Por esse prisma, compreende-se seu nativo frequentemente relacionado à guerra, sempre lutando ou em demonstrações de força. Logo em sua primeira aparição nas "Poesias americanas" dos "Primeiros Cantos", o indígena expõe seu teor belicoso em "O canto do guerreiro".

Nesse poema, o poeta outorga voz ao indígena, pois o eu-lírico é o próprio guerreiro, que nos primeiros versos adverte - "Façanhas de bravos / Não geram escravos, / Que estimem a vida / Sem guerra e lidar” (DIAS, 2000, p. 6-7) - alude-se ao conflito colonial, no qual os estrangeiros tentavam escravizar as populações nativas; mas, sobretudo, à capacidade de resistência desses povos, que não se deixam ser subjugados sem combate.

Adiante, nas estrofes II e III, apresentam-se as armas do guerreiro. Na primeira, o tacape: "Valente na guerra / Quem há, como eu sou? / Quem vibra o tacape / Com mais valentia? / Quem golpes daria / Fatais, como eu dou?” (DIAS, 2000, p. 7); na segunda, a flecha: "Quem guia nos ares / A frecha implumada ,/ Ferindo uma presa, / Com tanta certeza, / Na altura arrojada”. (DIAS, 2000, p. 7). Compreendendo ambos os artefatos como de natureza fálica, podem simbolizar a força masculina de coerção e ordem, perfeitamente consoante ao objetivo almejado pelo o poeta.

Tal força se enfatiza pelo teor épico que se impõe nos versos, efeito adquirido pelo ambiente em que o guerreiro se insere. As florestas tropicais aparecem enquanto elemento integrante da representação do indígena, criando uma atmosfera mítica. Na estofe VII, o guerreio canta: "Lá vão pelas matas; / Não fazem ruído: / O vento gemendo / E as matas tremendo [...] São eles - guerreiros, / Que faço avançar.” (DIAS, 2000, p. 9). Já na estrofe V, a fauna emerge como um meio para que o eu-lírico afirme sua coragem: "Quem há que me afronte!? / A onça raivosa / Meus passos conhece, / E a ave medrosa / Se esconde no céu /Quem há mais valente, / - Mais destro do que eu?” (DIAS, 2000, p. 8).

Já nos “Segundos Cantos”, de 1848, o nativo ressurge em "Tabira”. Não obstante ser a única poesia americana no livro, o literato entrega este longo poema de natureza épica, composto de vinte e cinco estrofes. Nele é narrada a história do líder-guerreiro da nação

1 Trata-se de uma seção do livro de poemas "Primeiros Cantos”, que compreende os poemas "Canção do exílio”, "O canto do guerreiro", "O canto do piaga”, "O canto do índio”, "Caxias” e "Deprecação”. 
Tabajara, Tabira, que, ao desacreditar o deus Tupã e firmar acordo com os portugueses, desencadeia a ira da nação Potiguar, o que o conduz à guerra.

É nesse contexto que o literato constrói passagens sangrentas como a do avanço de Tabira no campo de batalha - "Muitas setas cravejam Tabira: / Belo quadro! - mas vê-lo era horrível! / Porco-espim que sangrado e terrível” (DIAS, 2000, p. 238). Na estrofe seguinte, XXII, a imagem se torna mais apelativa no intento de ressaltar a índole resistente do guerreiro: "Tem um olho dum tiro frechado! / Quebra as setas que os passos lh'impedem / E do rosto, em seu sangue lavado, / Flecha e olho arrebata sem dó!” (DIAS, 2000, p. 239).

Ponderando sobre a literatura enquanto produto de seu tempo, é possível, diante de uma contextualização histórica, contrapor a crítica literária de Antonio Candido (2000, Vol. 2, p. 73), que considera o indianismo gonçalvino como um filamento da tendência europeia saudosista ao mundo feudal dos nobres cavaleiros. Além da conceituação do indígena das poesias americanas como personagem genérico e desprovido de particularidades. Certamente, há uma influência medievalista, principalmente portuguesa, na poesia do maranhense, determinando até mesmo sua métrica, entretanto, a representação aguerrida do indígena soa mais como uma retratação fidedigna da história nacional do que mera tentativa de acompanhar modismos românticos.

Para que se deduza tal assertiva, é necessário resgatar o quadro de constante conflito em que as nações indígenas brasileiras estavam inseridas. Fossem tais combates de cunho interno, ou contra os colonizadores, eles de fato nunca tiveram fim. Uma sucinta circunspecção pela história do Maranhão revela a continuidade das guerras. Segundo Socorro Cabral (2008, p. 53), durante o processo de conquista e ocupação do estado, nações como os Guanarés e os Barbados eram conhecidas como terror do território, oferecendo forte resistência à ocupação das margens do rio Itapecuru. Mesmo durante o período imperial, os confrontos entre a administração estatal e nações indígenas resistentes ao projeto civilizatório permaneciam ofícios do presidente da província maranhense, de 1837, indicam autorização e pagamento para organização de "entradas" e "expedições" contra populações indígenas não colonizadas, como os Guajajaras (MARANHÃO, 1997. p. 215, 216, 229).

A partir do exposto, observa-se que a representação do autóctone concebida pelo poeta não era alheia à realidade daqueles que viviam no Maranhão e em outras províncias. Quanto à problemática da generalização do indígena, não se deve omitir que os combates faziam parte do cotidiano de qualquer nação que não se dispusesse ao jugo do colonizador português, ou do estado imperial. Desse modo, o que o crítico avaliou como genérico, nada mais era do que os acontecimentos fatídicos a qualquer indígena, antes e durante os oitocentos.

Os estudos de cunho antropológico igualmente alimentaram a imaginação do literato, impelindo-o a determinadas reflexões sobre o caráter guerreiro dos autóctones. Evidência cabal desta assertiva se encontra na monografia "O Brasil e a Oceania", escrita para o Instituto Histórico e Geográfico Brasileiro, do qual Dias era membro entre os anos de 1850 e 1853 . Ao ponderar sobre os Tupi, o erudito expõe sua crença acerca da importância das guerras para essa nação: 
A renhida luta que em todas as partes os Tupys sustentavam contra as tribus do interior, poderia provir da sua índole bellicosa, - das suas instituições que consideravam o mais guerreiro como o mais digno de louvor e de estima, -reservando todos os prêmios da vida futura para aquelles que sabião affrontar a morte, as privações e os trabalhos com indomavel coragem (sic). (DIAS, 1869, Vol. VI, p. 12).

Nas disposições analisadas, é válido pensar a representação belicosa do indígena a partir do conceito de "herói” de José Murilo de Carvalho (1990, p. 53), para o qual os heróis são instrumentos de legitimação política, moldados conforme as aspirações de um regime, mas, para além, consoantes aos valores e ideias que atraem a população, que pode acolhê-lo ou rejeitá-lo, dependendo do nível de identificação com este. Por esse ângulo, a representação traz em si o projeto político da criação de uma identidade nacional, capaz de unificar a nação sob a administração do império, problemática decisiva nos oitocentos. O indígena de Gonçalves Dias, portanto, compreendeu perfeitamente os anseios de uma jovem nação, recém-independente, carente de uma origem desvinculada do velho mundo, e que ainda tentava fazer seu nome no cenário das grandes potências.

Para além dos estudos antropológicos, Gonçalves Dias conheceria o indígena pelo próprio sangue, porquanto era filho de um português com uma "mestiça”, nas palavras de seu amigo e biógrafo, Antônio Henriques Leal: "Corria pois nas veias do poeta o sangue misturado das três raças - europea, india e africana - que habitam o Brazil [...] (sic)” (LEAL apud DIAS, 1868, Vol. I, p. XXV). Outro fator que contribuiu amplamente para sua representação foi o convívio com os autóctones, desde sua tenra infância em Caxias, até na fase adulta em viagens pela Amazônia, consequentemente, o indígena "estava-lhe no corpo, alimentava-lhe a personalidade". (RICARDO, 2004, p. 77).

Logo, é válido afirmar que a representação imaginada pelo maranhense não se limitaria aos desígnios da unificação nacional. Expressaria, portanto, muito mais do poeta do que é possível apreender desprendido do seu contexto. Assim como a visão romântica que vai do "entusiasmo à melancolia, da nostalgia ao fervor, da exaltação confiante ao desespero" (NUNES, 2013, p. 52), a efígie do indígena transita entre extremos. O mesmo herói das matas tropicais que confrontou, com um mar de flechas e tacapes, os colonizadores, também lamentou melancolicamente o fim de suas antigas glórias e a perda do seu modo de vida.

Em "O canto do piaga”, vislumbra-se o oposto da força dos guerreiros, o protagonista é agora o Piaga (Pajé), pelo qual "Falam os Deuses nos cantos [...]” (DIAS, 2000, p. 10). O poema introduz uma atmosfera sombria, que aumenta progressivamente, à medida que o Piaga em sua caverna, durante a noite, não conseguindo dormir, recebe a visita de um ser etéreo: "Era feio, medonho, tremendo,/Ó guerreiros, o espectro que eu vi.” (DIAS, 2000, p. 11).

Adiante, na parte II, o "Espectro" começa a lhe falar, repreendendo-o por não se atentar aos presságios da natureza, e, ao fim, aconselha-o a ouvir o que tem a dizer, uma vez que os agouros preconizam a chegada de um grande monstro vindo do mar, forma como compreende a embarcação do colonizador, e lamenta, "Manitôs já fugiram da Taba! / Ó desgraça! Ó ruína! Ó Tupá!” (DIAS, 2000, p. 12). Curioso notar, a essa altura, como argumentou Paulo Franchetti (2007, p. 57), a apropriação de entidades Manitôs, os quais eram venerados pelos indígenas norte-americanos e cujo desaparecimento indicaria catástrofe eminente, por Gonçalves Dias, que os inclui como crença dos indígenas sul-americanos. 
No último verso, o brado ao "Tupá”, derivação da palavra “Tupã”, que na língua tupi designa o deus do trovão e dos raios - erroneamente associado ao deus cristão pelos missionários durante o trabalho de catequização, visto que possuía papel secundário na cosmogonia indígena segundo as hipóteses de Alfred Métraux (1950, p. 112-14) -, é posto enquanto lamento, frente aos presságios. Secundariamente, sugere a influência que a percepção cristã do panteão autóctone exerceu sobre o poeta, que se torna explícita nas notas explicativas, adicionadas aos poemas a fim de elucidar determinados termos de origem indígena, nas quais cita diversos relatos de viajantes e exploradores do território (DIAS, 2000, p. 481-484), entre esses, alguns cristãos como é o caso do Padre Simão de Vasconcelos e José de Anchieta.

Essa influência se esclarece melhor em "Deprecação", poema que trata da ruína trazida pelos colonizadores pela ótica indígena. O literato demonstra conhecer o teor das entidades, descrevendo o poder de Tupã: "Se os raios de morte, que vibram, são teus?" (DIAS, 2000, p. 17), contudo, associa a vinda dos colonizadores a Anhangá, entidade que os cristãos identificaram com o diabo: "Anhangá impiedoso nos trouxe de longe/Os homens que o raio manejam cruentos, / Que vivem sem pátria, que vagam sem tino / Trás do ouro correndo, voraces, sedentos." (DIAS, 2000, p. 17). Por conseguinte, o europeu configura a ganância, aquele enviado pela entidade maligna, com o fim de causar a destruição das nações indígenas.

A oposição entre Tupã e Anhangá, inexistente na religião tupi, designa dicotomias úteis ao ideal de patriotismo que os poemas deveriam inspirar, como Indígena / Colonizador, Brasileiro / Português e Bem / Mal. Uma vez que, como pondera Roger Chartier (2002, p. 2122), a imaginação deve tomar a representação por retrato fidedigno da realidade, adquirindo uma carga de imponência e respeitabilidade, tais dualidades na efígie do indígena legitimam a origem do povo brasileiro como descendente direto das nações autóctones sem qualquer conexão com os colonizadores lusitanos, estes, apresentados somente como um empecilho para a grandeza e a liberdade.

No entanto, o duelo não se limitava aos indígenas e colonizadores presentes na obra poética. Paralelamente, Gonçalves Dias travava uma batalha contra os padrões literários lusitanos, que se faz clara no desprezo à unidade métrica, além da celebração às temáticas nativas em detrimento das greco-latinas, marcantes na poesia lusa. No prólogo dos "Primeiros Cantos”, anuncia: “[...] menosprezo regras de mera convenção; adotei todos os ritmos da metrificação portuguesa, e usei deles como me pareceram enquadrar melhor com o que eu pretendia exprimir." (DIAS, 2000, p. 3).

As raízes dessa oposição eram mais profundas que o paradigma romântico da expressão acima da forma. Seu projeto pessoal era se tornar a maior figura da literatura brasileira. Em carta a Alexandre Teófilo de Carvalho Leal, seu melhor amigo e confidente, possivelmente de 1847, expôs:

Todos, sem exceção hão de confessar que Magalhães terá sido grande coisa, mas eu nem lhe sou discípulo, nem inferior. Todo o meu empenho, digo-te muito em segredo e todo cheio de vergonha, é ser o Primeiro Poeta no Brasil, e se houver tempo, o primeiro literato. (DIAS apud PEREIRA, 2018, p. 112).

Seria então imprescindível, para o poeta maranhense, introduzir novas temáticas 
à poesia nacional, já prescritas por outros autores, visto que, estar na vanguarda, lhe possibilitaria ascender na esfera literária do império. Para além da celebração das figuras nativas e a promoção de uma unidade nacional, Gonçalves Dias, certamente, buscava obter fama e prestígio, inclusive, superar seus contemporâneos.

\section{A RePresentaÇão COMO CRÍtica E AS IMAGENS do PASSAdo}

A figura do indígena enquanto representação do nacionalismo e liberdade do império já há muito se estabeleceu como cânone na obra gonçalvina. Analogamente, grande parte da fortuna crítica atribui ao conflito índio x colonizador, presente nas poesias americanas, somente o caráter de remontagem do passado colonial enquanto instrumento de rejeição lusófoba e de afirmação identitária nacional.

Em relação à nota presente na primeira edição de "Primeiros Cantos", em que o autor indica a necessidade de se cotejarem as poesias americanas com os relatos dos primeiros viajantes portugueses, alemães e franceses nas terras brasileiras, Paulo Franchetti argumenta:

\footnotetext{
Quando republicou os Primeiros Cantos na edição de sua poesia coligida, em 1857, a convenção indianista já estava estabelecida. A nota, portanto, era desnecessária e foi suprimida, pois a matéria indianista se situava, por si só, num passado quase imemorial, e já não se colocava a possibilidade de que os poemas fossem entendidos como representação de conflitos contemporâneos entre índios e brancos ou outras encarnações da oposição selvagem/ civilizado. (FRANCHETTI, 2007, p. 58, grifo do autor).
}

Indubitavelmente, não se pode relegar o fato de o indianismo ser um gênero constituído pelo imperativo de rememoração de um passado longínquo, em que a identidade nacional se dispõe. Contudo, ao tomar em conta certos aspectos da representação do indígena por Gonçalves Dias e do contexto político em que estava inserida, a possibilidade de uma analogia ao estado das populações indígenas no século XIX parece provável. Afinal, nenhuma representação é unilateral, pelo contrário, é multifacetada, à medida que contém os interesses dos grupos que a constroem.

Examine-se, atentamente, o final do poema "Tabira”. Após a derrota dos Potiguares pela nação Tabajara, liderada por Tabira, "Potiguares lá vão de fugida." (DIAS, 2000, p. 239), um pouco adiante, na estrofe XXV, surge o narrador, o qual expõe a origem da história:

\footnotetext{
'Este conto que índios contavam, /A desoras, na triste senzala; / Outros homens ali descansavam, / Negra pel'; mas escravos também. / Não choravam, somente na fala / Era um quê da tristeza que mora / Dentro d'alma do homem que chora / O passado e o presente que tem!'. (DIAS, 2000, p. 240).
}

Como se torna perceptível, a última estrofe edifica um elo entre o passado e o presente. O passado dos combates coloniais, os quais ocupam volumosa parte da narrativa do poema, influi em um presente desastroso: os indígenas, juntamente com os africanos, escravizados. A despeito de o fenômeno escravista ter ocorrido igualmente nos períodos de colônia e de império, é indeclinável buscar ler esses versos sob a ótica oitocentista, no intento de evitar anacronismos.

Para o indivíduo que lesse a última estrofe, em meados do século XIX, período de sua publicação, certamente pensaria tratar-se de sua contemporaneidade, uma vez que, os portugueses já não eram mais soberanos das grandes propriedades de terra, a elite escravocrata 
era amplamente brasileira. Quanto ao indígena, conforme já exposto, permanecia enquanto problemática séria para o império, não apenas no estado do Maranhão, mas em todo o território.

De fato, mesmo após a independência e consolidação do estado brasileiro, a forma de lidar com os indígenas permaneceu sem grandes alterações. O "Regulamento das missões de catequeses e civilização dos índios", de 1845, insistia, assim como o "Diretório que se deve observar nas Povoações dos Índios do Pará, e Maranhão, enquanto sua majestade não mandar o contrário", este de 1758, em uma assimilação dos indígenas por meio do imperativo de requerimento da cidadania brasileira através do trabalho. Por meio dos chamados "aldeamentos", essas legislações buscavam organizar a vida dos autóctones aos moldes civilizacionais europeus. Os aldeões deveriam fixar trabalho na lavoura, fornecer serviços remunerados em localidades adjacentes, alistarem-se no exército e aprenderem profissões. Além disso, preconizou-se, no século XIX, o retorno da instrução jesuítica nos povoamentos aos moldes quinhentistas, sendo competência do diretor geral: "Esmerar-se em que lhes sejão explicadas as maximas da Religião Catholica, e ensinada a doutrina Christã [...] (sic)” (REGULAMENTO..., 1845, Arts. $1^{\circ}$, §§ 20 $0^{\circ}$.

Por esse ângulo, são compreensíveis os versos de "O canto do Piaga", "Vem trazer-vos crueza, impiedade - / Dons cruéis do cruel Anhangá; / Vem quebrar-vos a maça valente, / Profanar Manitôs, Maracá." (DIAS, 2000, p. 12-13), nos quais o símbolo de poder fálico indígena é destruído, declarando a derrocada dos povos, conjuntamente ao detrimento do caráter sagrado pertencente aos espíritos e aos instrumentos sonoros. A perda destes artefatos é, por conseguinte, a própria perda de identidade dos indígenas brasileiros mediante o intenso processo de aculturação sofrido desde os primórdios do século $\mathrm{XV}$, com os primeiros contatos, e que se estendeu até o XIX, no qual atinge um status de institucionalização pelo estado imperial.

No campo de embate das representações, portanto, o indígena de poemas como "Deprecação", "O canto do Piaga" e em certos trechos de "Tabira", que descreve a perda de seus traços definidores, opõe-se àquele representado, em variadas legislações, enquanto um indivíduo desprovido de cultura, necessitado de instrução religiosa e civilidade europeia. Considerando que as representações estão circunscritas pelas aspirações dos grupos que as concebem paralelamente à realidade social, torna-se forçoso compreender a situação social daqueles que as designam (CHARTIER, 2002, p. 17).

Nessa perspectiva, o indígena enquanto crítica velada adquire maior verossimilhança ao se observar a complexa posição do literato frente ao governo imperial. $\mathrm{Na}$ condição de funcionário público, nomeado professor de latim e história no colégio D. Pedro II pelo marquês de Olinda, como afirma a biógrafa Lúcia Miguel Pereira (2018, p. 130), e mais tarde, membro do IHGB, instituição coordenada diretamente pelo imperador, criticar negativamente o estado impediria Gonçalves Dias de alcançar seus objetivos enquanto figura pública.

Irremediavelmente, uma crítica mais severa ocorreria com a publicação, na revista "Guanabara”, do poema em prosa "Meditação", em 1850, ou seja, apenas dois anos depois de “Tabira” vir à tona nos "Segundos Cantos”. Construção literária que mescla visões oníricas com uma linguagem bíblica, o poema realiza rigorosas censuras sobre a escravidão e o atraso do império, ainda muito vinculado com práticas coloniais. 
Atribuindo isso, em conjunto a uma reflexão sobre os lamentos, profecias de ruína e o estado iminente de dominação presentes nas poesias americanas, torna-se árduo imaginar que representação arquitetada pelo poeta, esse que tanto apreciava os primeiros habitantes do Brasil, não fosse, através dos conflitos primordiais da colônia, uma analogia à violência sofrida por essas populações diante do processo assimilador do império.

\section{RECEPÇÃO, DISSEMINAÇÃO E INFLUÊNCIA}

Um dos grandes méritos da carreira literária de Gonçalves Dias foi sua rápida ascensão à fama e ao reconhecimento como o maior poeta do império, ao contrário de muitos casos na literatura nacional. É unânime que seus "Primeiros Cantos" foram um sucesso, tanto em solo brasileiro como em português, conforme indica a crítica realizada pelo escritor português Alexandre Herculano, em "O futuro literário de Portugal e do Brasil”, publicado em 1847. Em seus comentários, o romântico português declarava, alarmado, o fim da literatura lusa e o florescer da literatura brasileira no novo mundo:

[...] Brazil. E' um mancebo vigoroso que derriba um velho cachetico, demente e paralítico. O que completa, porém, a prova é o exame não comparativo, mas absoluto de algumas das modernas publicações brasileiras.

Os Primeiros Cantos são um bello livro; são inspirações de um grande poeta. A terra de Santa Cruz que ja conta outros no seu seio, pode abençoar mais um illustre filho (sic). (HERCULANO apud DIAS, 1857, p. XVI, grifo do autor).

É bem documentada a impressão de suas obras, tanto em território nacional, quanto internacional. Desse modo, é plausível afirmar que a obra poética do maranhense tenha alcançado certa parcela da população com background intelectual necessário para a compreensão profunda de seus versos. Como aponta Gilberto Freyre (2009, p. 60-61), próximo ao fim do século XIX, grande parte da elite brasileira ainda se encontrava nos padrões culturais pertencentes aos fins do XVIII e ao início do XIX. Tomando por base essa conjuntura, a poesia de Dias provavelmente atingiu prontamente os gostos da época, dada a suas características neoclássicas e medievalistas, que ainda deviam algo à literatura portuguesa, aliadas à nova sensibilidade romântica e nativista.

O estudo das representações conduz, para além dos seus traços constitutivos e formadores, a uma reflexão sobre as leituras e apropriações historicamente realizadas pelos leitores da mesma (CHARTIER, 2002, p. 23-24). Nesse sentido, considerando o campo literário, as obras gonçalvinas foram lidas e absorvidas por seus contemporâneos como José de Alencar, Bernardo Guimarães, Machado de Assis, entre muitos outros. Seu estilo único de representar o indígena, ao que parece, alterou profundamente o panorama da literatura nacional, de modo a se tornar, direta ou indiretamente, uma inspiração para qualquer tratamento artístico da singularidade brasileira.

Ao tratar da obra de José de Alencar, "Iracema”, Machado de Assis (2019, p. 1) no "Diário do Rio de Janeiro", inspirado por autores como Gonçalves Dias, Basílio da Gama e Gonçalves de Magalhães, argumenta que o alicerce da crítica à escola poética indianista seria um quadro de literatos que somente incluiria palavras e motivos indígenas em sua poética sem captar, de modo profundo, a sensibilidade dos verdadeiros indianistas. No entanto, tal fator não diminuiria os méritos dessa escola, que na obra dos três mencionados encontraria 
modelos de forte criatividade.

Certamente, Machado de Assis crera nas próprias palavras, e contribuiu para o indianismo clamado por Dias no ano de 1875, em seu "Americanas", conjunto de poesias de cunho nativista. A influência da lira do maranhense é inegável, a epígrafe do livro apresenta um verso da terceira estrofe do épico "Os Timbiras", "filha melhor do Eterno, América!". Ainda nesta coletânea, presta máxima homenagem ao romântico, dedicando-lhe o poema "A Gonçalves Dias" a sua vida e obra: "Como a harpa dos exules prophetas, / A heroica tuba. Elle a embocou, vencendo/ Co'a lembrança do ninho seu paterno / Longas saudades e miserias tantas. / Que monta o padecer? Um so momento/As maguas Ihe pagou da vida [...] (sic). (ASSIS, 1875, p. 142).

A representação belicosa do indígena aos moldes de "Canto do guerreiro" e "Tabira”, embora não seja matéria principal nessa coletânea, faz-se presente em certos trechos de "Potyra", nos quais é notável a exaltação da força do indígena em combate: "Heroe lhe chamam / Quantos o hão visto no fervor da guerra / Medo e morte espalhar entre os contrarios / E avantajar-se nos certeiros golpes / Aos mais fortes da tribu; (sic)" (ASSIS, 1875, p. 9).

José de Alencar - reconhecido principalmente devido a suas ficções de cunho indianista como "O Guarani", "Iracema” e "Ubirajara”, sendo o primeiro desses considerado por José Veríssimo (2019, p. 120) de análogo valor para a ficção em prosa que os "Primeiros Cantos" para a poesia brasileira -, também se aventurou na poesia lírica indianista com forte influência gonçalvina em "Os filhos de Tupã”, experimento para um épico que somente chegou até a terceira parte, a despeito do projeto inicial, que visava a dez. Logo durante a abertura é perceptível a atmosfera grandiosa através da descrição do cenário e das indicações quanto ao som produzido pelos nativos: “Ao deserto, minh'alma! Sôbre os píncaros / Da branca penedia, e enquanto o vento / Nos antros da montanha ulula e brame, / Solte a rude pocema o canto fero / Dos filhos de Tupã. E ruja a inúbia / Troando pela várzea os sons bravios." (ALENCAR apud AMORA, 1965, p. 56).

A representação do indígena de Dias também foi apropriada em forma de paródia por Bernardo Guimarães, em seu "O elixir do Pajé”, o qual retrata a história de um chefe curandeiro que busca recuperar seu vigor sexual. Mesmo havendo uma crítica à tendência indianista criada pelo poeta do exílio, ao tomá-la por modelo, ainda que ironicamente, Bernardo Guimarães ecoa passagens clássicas do romantismo (JOBIM, 2006, p. 205-206): "Mas neste trabalho, / dizei, minha gente; / quem é mais valente, / mais forte quem é / Quem vibra o marzapo / com mais valentia? / Quem conas enfia / com tanta destreza?" (GUIMARÃES, 2020, p. 4). Confessadamente uma referência aos versos da estrofe II de "O canto do Guerreiro" em "Primeiros Cantos": "Valente na guerra / Quem há, como eu sou? / Quem vibra o tacape / Com mais valentia? / Quem golpes daria / Fatais, como eu dou? / Guerreiros, ouvi-me; /- Quem há, como eu sou?” (DIAS, 2000, p. 7).

Cassiano Ricardo (2004, p. 133) aponta o poeta maranhense como forte influência para o indianismo moderno, que a partir dos anos 20 buscava no indígena parte da origem da singularidade cultural e ontológica brasileira. Por esse prisma, a figura do indígena reaparecerá em uma faceta diversa, como em "Macunaíma” de Mário de Andrade, enquanto em manifestos como o da "Antropofagia" de Oswald de Andrade e o da "Anta" de Plínio Salgado, Menotti Del Picchia e Cassiano Ricardo o indianismo possui um papel indelével. Ainda nessa perspectiva, 
Alfredo Bosi (2017, p. 364) argumenta que parte dos anseios modernistas eram baseados na necessidade de uma renovação estética primitivista das origens nacionais, sobretudo as raízes indígenas e negras, o que em certo sentido, não destoa da busca de Gonçalves Dias, através de seu indígena, por uma identidade nacional.

No que diz respeito ao campo das representações, é eminente a absorção, em certo nível, do indígena de Gonçalves Dias pelas personalidades literárias contemporâneas, mas igualmente, ressoando nas gerações posteriores, o que, de fato, concretiza-o enquanto personagem recorrente na literatura brasileira. Por esse ângulo, vale mencionar o enquadramento da representação feita por Gonçalves Dias na ideia de "percepção criadora” (SANTOS, 2011, p. 213), ou seja, uma imagem ou descrição que perdura ao longo do tempo, sobrevivendo nas criações de outros autores, através do capital simbólico daquele que lhe deu origem.

\section{CONSIDERAÇÕES FINAIS}

Uma vez que a historicidade de uma construção literária é velada, sua compreensão pode se tornar parcial, ou mesmo anacrônica. Uma aproximação coordenada entre a história e a literatura amplia, consideravelmente, o horizonte interpretativo de uma representação, como demonstrado nessa incursão. Por esse ângulo, reconciliar esses âmbitos, é uma possibilidade para a produção de uma história da literatura integrada, e a representação, dispositivo teórico eficaz.

O cotejo de diversas fontes paralelas aos livros de poesias permite entrever a gama de conflitos que envolviam a percepção do que era o indígena para a literatura, para o estado e para o poeta maranhense de forma mais íntima. Além de como esses diversos espectros se manifestaram de forma explícita ou velada nos versos, que se encontravam carregados de planos, entre os quais o de alcançar o posto de maior poeta da nação. Uma nova dimensão do ofício literário se expõe diante dessa documentação, à medida que a criação poética não é percebida pelo literato somente como um fim em si mesma, mas também, enquanto um meio de ascensão social.

Adentrar na representação do indígena concebida por Gonçalves Dias conduz o trabalho historiográfico, em suma, a uma imersão adentro de sua temporalidade, ambições e estado de espírito. A tendência romântica à ambivalência, parte integrante da personalidade do literato, é transfigurada para o nativo de sua obra, que, inserido simultaneamente em atos de bravura e em lamentos frente à colonização, traduz o conflito interno do poeta. Esse que, por um lado, fez uso dessa efígie característica do novo mundo como símbolo da força nacional, e por outro, instrumentalizou tal figura como uma ferramenta de crítica às políticas indigenistas no século XIX.

Convivendo intimamente com os indígenas, desde a infância e durante a vida adulta, além de carregar tal etnia em seu sangue, o poeta a influiu em sua própria representação. Assim, como "o conquistador irá escrever o corpo do outro e nele traçar a sua própria história." (CERTEAU, 1982, p. 9, grifo do autor), Gonçalves Dias inscreverá a si mesmo na imagem do indígena brasileiro, aprisionando neste, suas lutas, projetos e emoções.

Por fim, para além da especificidade da representação do indígena arquitetada pelo poeta maranhense, essa se insere em uma vasta constelação, que se desenvolve ao longo da história, 
legitimando ações e discursos subordinados a outros interesses e propósitos. Apreender, em maior complexidade, o conjunto dessas representações, além da maneira como estas se relacionam em seus diversos campos de atuação, constantemente em combate por hegemonia, seria um conduto interessante, e ainda pouco explorado, para uma história da intelectualidade brasileira nos oitocentos, mas que conserve em seu escopo vínculos concretos com o social.

\section{REFERÊNCIAS BiBLIOGRÁFICAS}

\section{DocumentaIs:}

ANAIS DA BIBLIOTECA NACIONAL VOL. 84. Correspondência ativa de Antônio Gonçalves Dias. Divisão de publicações e divulgação: Rio de Janeiro, 1971.

ASSIS, Machado de. Americanas. Rio de janeiro: B. L. Garnier, 1875. Disponível em: https:// digital.bbm.usp.br/handle/bbm/4508. Acesso em: 16 ago. 2020.

DENIS, Ferdinand. Résumé de l'histoire littéraire du Portugal, suivi du résumé de l'histoire littéraire du Brésil. Paris: Lecointe et Durey Libraries, 1826. Disponível em: https://bibdig. biblioteca.unesp.br/handle/10/25963. Acesso em: 20 set. 2020.

DIAS, Gonçalves. Cantos: Collecção de Poezias. 2. ed. Leipzig: F. A. Brockhaus, 1857. Disponível em: https://digital.bbm.usp.br/handle/bbm/4423. Acesso em: 12 jul. 2020.

DIAS, Gonçalves. Obras póstumas de A. Gonçalves Dias: precedidas de uma notícia da sua vida e obras pelo dr. Antonio Henriques Leal. Vol. I. São Luís, Maranhão: Bellarmino de Mattos, 1868. Disponível em: https://digital.bbm.usp.br/handle/bbm/4112. Acesso em: 20 nov. 2019.

DIAS, Gonçalves. Obras póstumas de A. Gonçalves Dias: precedidas de uma notícia da sua vida e obras pelo dr. Antonio Henriques Leal. Vol. VI. São Luís, Maranhão: Bellarmino de Mattos, 1869. Disponível em: https://digital.bbm.usp.br/handle/bbm/4445. Acesso em: 20 nov. 2019.

DIRETÓRIO QUE SE DEVE OBSERVAR NAS POVOAÇÕES DOS ÍNDIOS DO PARÁ, E MARANHÃO, ENQUANTO SUA MAJESTADE NÃO MANDAR O CONTRÁRIO. 1758. Disponível em: http://lemad.fflch.usp.br/sites/lemad.fflch.usp.br/files/201804/Diretorio_dos_ indios_de\%29_1757.pdf. Acesso em: 8 jan. 2020.

GUANABARA, Revista Mensal Artistica, Scientifica e Literaria. Dirigida por: Manoel de Araújo Porto-Alegre, Antonio Gonçalves Dias, Joaquim Manoel de Macedo. Tomo I. Rio de Janeiro: Tipografia Guanabarense de L. A. F. Menenezes, 1850. Disponível em: http://hdl.handle. net/fcrb/244. Acesso em: 22 ago. 2019.

NITHEROY, Revista Brasiliense: Sciencias, Lettras e Artes. Tomo I. N ${ }^{\circ} 1$. Paris: Dauvin et Fontaine, Libraries, 1836. Disponível em: https://digital.bbm.usp.br/handle/bbm/6859. Acesso em: 10 ago. 2020.

REGULAMENTO ACERCA DAS MISSÕES DE CATECHESE, E CIVILISAÇÃO DOS IUDIOS. Decreto n. 426, 24 de julho de 1845, por José Carlos Pereira de Almeida Torres com rubrica do Imperador Dom Pedro II. Disponível em: http://legis.senado.leg.br/norma/387574/ publicacao/15771126. Acesso em: 1 fev. 2020. 


\section{BiBLIOGRÁFICAS:}

AMORA, Manoel Albano. José de Alencar, poeta. Ceará: Academia cearense de Letras, 1965. Disponível em: http://www.academiacearensedeletras.org.br/revista/revistas/1965/ ACL_1965_05_Jose_de_Alencar_Poeta_Manoel_Albano_Amora.pdf. Acesso em: 25 mar. 2020.

ASSIS, Machado de. José de Alencar: Iracema. Disponível em: http://machado.mec.gov.br/obracompleta-lista/itemlist/category/28?order=year\&start=12. Acesso em: 17 jun. 2019.

BOSI, Alfredo. História concisa da Literatura Brasileira. 52. ed. São Paulo: Cultrix, 2017.

CABRAL, Maria do Socorro Coelho. Caminhos do Gado: a conquista e ocupação do sul do Maranhão. 2. ed. São Luís: Edufma, 2008.

CANDIDO, Antonio. Formação da literatura brasileira: momentos decisivos. Vol. 1, 2. 6. ed. Belo Horizonte: Ed. Itatiaia, 2000.

CARVALHO, José Murilo de. A Formação das Almas: o imaginário da República no Brasil. São Paulo: Companhia das Letras, 1990.

CERTEAU, Michel de. A escrita da história. Rio de Janeiro: Forense-Universitária, 1982.

CHARTIER, Roger. História Cultural: entre práticas e representações. Algés: Difel, 2002.

DIAS, Gonçalves. Cantos. São Paulo: Martins Fontes, 2000.

FALBEL, Nachman. Os fundamentos históricos do romantismo. In: GUINSBURG, Jacob (Org.). $\mathbf{O}$ Romantismo. 4. ed. São Paulo: Perspectiva, 2013. p. 23-50.

FRANCHETTI, Paulo. Estudos de literatura brasileira e portuguesa. São Paulo: Ateliê Editorial, 2007.

FREYRE, Gilberto. Vida social no Brasil nos meados do século XIX. 4. ed. São Paulo: Global, 2009.

GUIMARÃES. Bernardo. O elixir do Pajé. Disponível em: http://www.dominiopublico.gov.br/ pesquisa/DetalheObraDownload.do?select_action $=\&$ co_obra $=16583 \&$ co_midia $=2$. Acesso em: 3 fev. 2020.

IMPRENSA NACIONAL. Collecção das leis do Brazil. Rio de Janeiro: [s. n.], 1891. Disponível em: https://www2.camara.leg.br/atividade-legislativa/legislacao/colecao-anual-de-leis/copy_of_ colecao1.html. Acesso em: 12 mar. 2019.

JOBIM, José Luís. Indianismo literário na cultura do romantismo. Revista de Letras UNESP. São Paulo, Vol. 46, n. 1, p. 191-208, jan./jun., 2006. Disponível em: https://periodicos.fclar.unesp.br/ letras/article/view/48/42. Acesso em: 12 jun. 2019.

MARANHÃO, Arquivo Público do Estado. Repertório de Documentos para a História Indígena no Maranhão. São Luís: SECMA, 1997.

MARTIUS, Karl Friedrich von. Como se deve escrever a história do Brasil. Revista de História de América. n. 42, p. 433-458, dez., 1956. Disponível em: https://www.academia.edu/16092043/ Como_se_deve_escrever_a_Historia_do_Brasil_Author_s_Karl_Friedrich. Acesso em: 14 abr. 2019. MÉTRAUX, Alfred. A religião dos Tupinambás: e suas relações com as demais tribos Tupiguaranis. Tradução por Estevão Pinto. São Paulo: Comp. Editora nacional, 1950.

NUNES, Benedito. A visão romântica. In: GUINSBURG, Jacob (Org.). O Romantismo. 4. ed. São 
Paulo: Perspectiva, 2013. p. 51-74.

PEREIRA, Lúcia Miguel. A vida de Gonçalves Dias. Brasília: Senado Federal, Conselho Editorial, 2018.

RIBEIRO, Luís Felipe. Mulheres de papel: um estudo do imaginário em José de Alencar e Machado de Assis. Ed. EDUF: Niterói, 1996.

RICARDO, Cassiano. Gonçalves Dias e o Indianismo. In: COUTINHO, Afrânio. A literatura no Brasil. 7. ed. São Paulo: Global, 2004. p. 70-138.

SAMPAIO, Patrícia Melo. Política indigenista no Brasil imperial. In: GRINBERG, Keila; SALLES, Ricardo. O Brasil Imperial. Vol. 1: 1808-18031. Rio de Janeiro: Civilização Brasileira, 2011. p. 177-201.

SANTOS, Raimundo Lima dos. O sertão inventado: a percepção dos sertões maranhenses pelo olhar de Francisco de Paula Ribeiro. Revista de História Regional. vol. 16, n. 1, p. 209-234, 8 abr. 2011. Disponível em: https://revistas2.uepg.br/index.php/rhr/article/view/2429. Acesso em: 23 ago. 2020.

VERÍSSIMO, José. História da literatura brasileira. Disponível em: http://www. dominiopublico.gov.br/pesquisa/DetalheObraDownload.do?select_action=\&co_obra=2127\&co_ $\underline{\text { midia }=2}$. Acesso em: 25 fev. 2019. 